\title{
Red Cross spinal injury project in Bucharest, Romania
}

\author{
A Soopramanien MD $\mathrm{PhD}$ \\ International Federation of Red Cross and Red Crescent Societies, PO Box 372-1211 \\ Geneva 19, Switzerland.
}

\begin{abstract}
Inadequate medical facilities with lack of specialised drugs and other essential medical items, scientific isolation of medical staff, unavailability of orthoses and wheelchairs: such were a few of the problems identified in Bucharest in July 1991. The aim of the federation at the start of the project was to launch an action in many directions using two basic principles: using local means including human resources, and improving the existing facilities instead of erecting new buildings.

Training of the staff goes side by side with the practice of total initial care. The family is taught to position and turn patients, practise chest physiotherapy and has become a major psychological and emotional support. An orthopaedic workshop has been set up to provide orthoses and to supervise the construction of wheelchairs in a local factory. The social situation of patients is assessed to initiate sociai integration in the community. Home visits are organised to offer advice for adaptations.

The implementation of these actions is difficult in a country which has to solve many economic problems.
\end{abstract}

Keywords: spinal cord injury; Romania; total care unit; epidemiology.

\section{Introduction}

Romania, famous for its painted monasteries, was brought into the limelight with the live coverage of the Christmas 1989 political turmoil which led to many citizens being either killed or injured. Among the latter were 16 spinal cord victims who were all flown to different parts of western Europe for acute management. However generous this offer, it could not meet the requirements of the life-time care for those who had been injured.

Such considerations prompted the Romanian authorities and the Romanian Red Cross Society to seek international help through the Red Cross movement. If it could be proved that the spinal cord injured constituted a vulnerable group within Romania, the Romanian Red Cross Society would qualify to receive support from the International Federation of the Red Cross and Red Crescent Societies. In 1989 the latter did commit itself in its strategic work plan for the nineties to 'play a much stronger role in promoting the development that improves the capacity of vulnerable communities and individuals'.

\section{Justifying the project}

Epidemiological studies conducted by the federation in collaboration with the medicosurgical teams of the Dr Gheorghe Marinescu Hospital, Bucharest, showed that 300 acutely spinal injured patients (Fig 1) are admitted each year in Bucharest, which has a catchment area of $50 \%$ of the country. This is an incidence of 26 patients per million inhabitants.

More than $50 \%$ have cervical or high thoracic injuries; the main causes of injury being falls from heights and from carts (onto the head) or diving accidents (Fig 2).

In July 1992, this pattern was confirmed 
since 52 new patients were admitted, of whom $40 \%$ had fallen from a cart and $20 \%$ had sustained diving accidents. Fifty percent are less than 40 years of age, $80 \%$ are male (Fig 3), and $70 \%$ have limited financial resources (Fig 4).

Thus, the number of spinal cord injured in general, and in particular the number with high lesions is impressive and important. Their management has previously been unsatisfactory because of scientific isolation and lack of facilities.

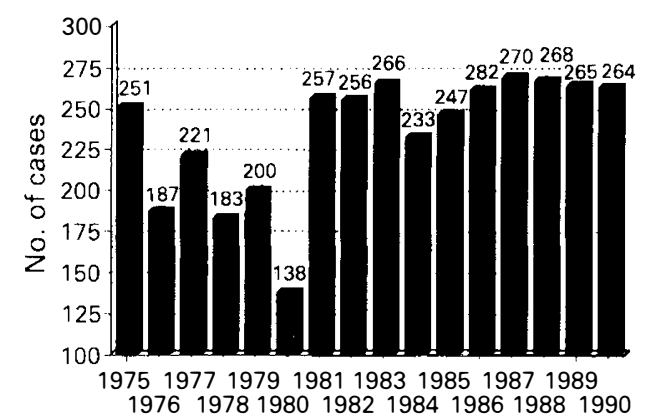

Figure 1 Number of admissions per year.

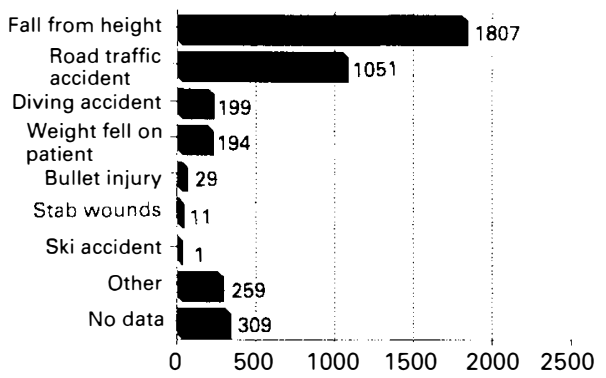

Figure 2 Causes of injury (1975-1990).

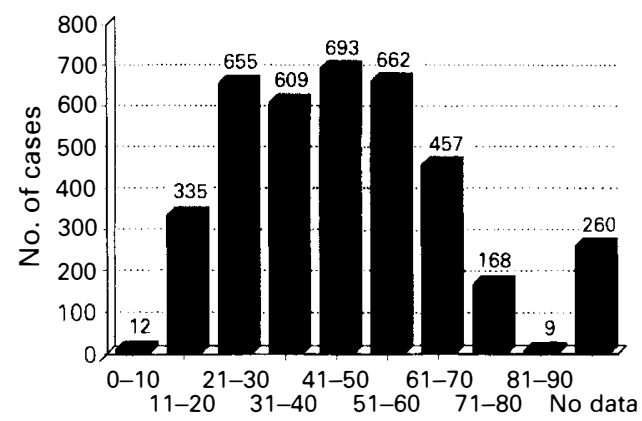

Figure 3 Age at time of injury.

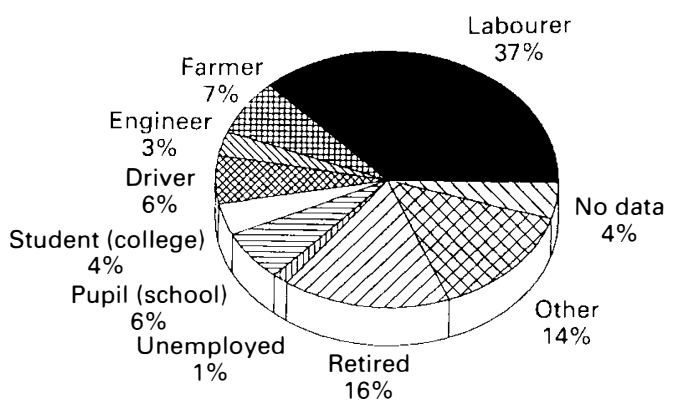

Figure 4 Distribution by occupation (1/1/92$1 / 7 / 92)$.

Other problems identified were a lack of beds on the 10th floor, so that only $20 \%$ of acute admissions could be accepted for rehabilitation. Thus many patients were discharged home soon after surgery, without having been rehabilitated, thus being confined to bed, or never leaving their room or house for years. Wheelchairs were rare as they were only free for the $14 \%$ who had had an accident at work. Others could purchase standard chairs with fixed armrests, but there was a waiting list and many went home without a wheelchair and were confined to bed. Doctors, physiotherapists, and nurses were all in insufficient numbers but were doing their best in difficult conditions with limited access to international influences, books and articles. The team could not properly plan the discharge of patients, as no facilities were provided for home visits to assess patients' social and rehabilitation needs.

The health authorities cannot easily reverse the situation, as the country is facing acute problems in all fields of medicine. A recent World Bank report states that: 'Life expectancy has declined over the last decade, infant mortality has risen and infectious diseases are still widespread. Drugs and medical consumables are in extremely short supply and much equipment is obsolete and stands idle for lack of spare parts. Attempts to improve the population's health status are taking place against a background of economic crisis'. Spinal cord injury care therefore will not be considered a priority for years.

Yet persons with spinal cord injuries are individuals with an intact brain who have 
experienced physical and psychological damage with paralysed limbs, bladder and bowel. How can humanity confine to bed a young man and let him die slowly of urinary infection, pressure sores and depression? This group constitutes a vulnerable community. Thus was born the spinal injury project.

\section{Setting up the project}

An agreement between the International Federation of the Red Cross and Red Crescent Societies (Federation), the Romanian Red Cross Society and the Romanian authorities to establish a spinal injury project in Romania was signed in August 1991.

Based on the experience gained elsewhere and after discussions with the National Red Cross societies financing the project, it was decided to:

\section{Build an expatriate team}

National Red Cross and Red Crescent Societies were asked to provide and support two nurses, two physiotherapists, two occupational therapists and one orthopaedic technician, in addition to the medical doctor team leader and a social worker, a position which for 6 months was held by an expatriate volunteer.

\section{Define the physical set-up}

The care of patients from the day of injury in the acute surgical and rehabilitation wards has been introduced. A serious effort has been made to group the surgical patients together.

In the intensive care unit, a room is allocated to the team. In the surgical wards, most patients are now in a separate unit, but others are still scattered over three other floors. The existing neurological rehabilitation floor has been divided into two distinct parts with half of the unit treating exclusively 28 traumatic spinal injured patients. The dining hall has been converted into a physiotherapy area with necessary facilities. Bathrooms have been adapted and are more functional than cosmetic, and a social activities room has been set up. A special surgical spinal operating theatre is being organised. On the basement floor, rooms have been made available for an orthopaedic workshop. The team has thus improved the existing facilities rather than asked for new expensive buildings.

\section{Determine the clinical strategy}

The concept of 'total initial care' has been promoted by ensuring early intervention in areas like bowel and bladder management and pressure sore prevention. The family helps to compensate for lack of staff on all floors. Modern thinking has been introduced for surgical and conservative management. Team work is emphasised with multidisciplinary short, medium and long term goals, protocols for bladder management and the use of cervical collars and braces. Stress is laid on mobility with the provision of wheelchairs, walking aids and orthoses to help overcome the many architectural barriers at home.

\section{Train the local staff and arrange scientific exchanges}

Theoretical classes consisted of a total of 100 hours of lectures on topics relative to spinal cord injuries. Practical sessions were also organised. The best candidates are being sent abroad for one month's training in spinal centres.

\section{Favour local solutions}

The philosophy is both to reduce the cost of the project to ensure its long term survival and to avoid dependence on foreign supplies. A contract has been signed with a local factory for the production of wheelchairs and walking aids under our guidance. The hunt for local materials has produced encouraging results. A wheelchair costs $\$ 120$ (US). The same effort is being made to obtain drugs.

\section{Encourage social integration, vocational training and social help through home visits} A social department was opened in February 1992 and has established contacts with the authorities, but much work is required 
since prejudice still exists against the paralysed person and his/her wheelchair. The project has encouraged the establishment of an association for spinal injured which is seeking official recognition.

Thirty-five homes have been visited, mainly by occupational therapists and social workers. The work has so far consisted more in listing problems than in offering practical help. The federation is trying to persuade the Romanian authorities to take a more active role concerning social problems. A few patients have so far shown how creative they can be and deserve to be encouraged and helped.

\section{Initiate epidemiological studies}

The findings of the retrospective (19751991) and prospective (1/1/92-1/7/92) studies have proved useful for the planning of the project.

\section{Set up a secretariat}

The secretariat of the project plays an important role and handles translations of teaching material, provides secretarial support, purchases materials, and helps with epidemiological studies and computer programming. The Romanian staff are assuming increasing responsibilities so that they can continue the work after the withdrawal of the federation.

\section{Analysis of the project}

Success is dependent on a high level of motivation, the setting up of well defined goals within the federation team and effective collaboration between the nine expatriates and local personnel.

The project has been fortunate in recruiting hard working, motivated professionals. Expatriates from various countries, social and professional backgrounds define a common approach and foster better understanding during the regular team meetings. Protocols have been defined on how to manage spinal cord injuries at the different stages and on the use of cervical collars and braces prior to mobilisation.

Relations between expatriates and local personnel can be difficult, mainly through lack of understanding of local culture by the former, and suspicion of the real motivations of the federation staff by the latter. Every effort is made in the recruitment of expatriate staff to strike a balance between professional capability and cross-cultural adaptibility.

The suspicion of Romanians is understandable given their history, and the humiliation that has come with many obsolete materials or expired drugs being donated to them since 1990. It is encouraging to report that the spirit of federation involvement is now fully understood and the Romanian staff offer the warmth of their welcome, along with their intelligent and active support.

Thanks to this excellent atmosphere, the training of staff is being pursued on both informal and formal modes and much stress is laid on involving the families in turning and positioning patients, in chest physiotherapy and in physical, psychological and emotional problems. It is difficult at times to convince the staff to accept the presence of these carers on a 24 -hour basis.

Nurses, nurse helpers, physiotherapists, and occupational therapists are increasingly cooperative, as are the surgeons who now keep the patients longer in their wards and also accept conservative management. Rehabilitation doctors question their own methods of medical management within a team that has worked together over 16 years. The federation is very grateful to them for such excellent collaboration.

Patients are now being provided with total initial care from the day of admission. Pressure sores in acute patients are very rare today compared to an incidence of $8 \% 8$ months ago. Chest physiotherapy and closer clinical follow up have reduced the death rate in the first month from $22 \%$ to $8.9 \%$.

During the acute phase, the chest, heart, bowel sounds and limb size are closely monitored. Routine anticoagulation cannot be afforded and only clinically obvious deep vein thrombosis, seen in $8 \%$ of the patients, is treated.

Patients can only stay 3 months for rehabilitation, which is too short. Braces and collars made in the workshop have brought new possibilities in rehabilitation. 
Bladder and bowel management attempts to follow the same principles as in other centres, but unfortunately there is an acute lack of condoms, catheters and urine bags within the country and the team is studying a long term solution to this problem, as well as to wheelchair and orthosis production.

The project relies on the Romanian Red Cross Society and the Spinal Injuries Association (SPIROM) to bring an awareness of the need for social integration, vocational training and the raising of funds to help patients at home overcome architectural barriers.

After the withdrawal of the federation, the level of care achieved must be maintained and improved. This demands planning for the project to be technically and financially self reliant. Trained staff need to be supported and basic care provided in hospital at a reasonable cost with drugs being easily and cheaply available, even in remote villages. Ensuring a high standard of care should make it easier for the centre to receive support through a fund-raising programme which could be organised in collaboration with the Romanian Red Cross Society. The success or failure of this enterprise will weigh much in the federation's decision to be involved in other parts of the globe.

\section{Learning from this project}

The main lessons derived from the project are set out below.

There is an urgent need for a safety campaign to decrease the number of cart and diving accidents.

The cost of treating one spinal patient is $£ 30$ per day inclusive of expatriate salary, technical and medical equipment and drugs. Basic equipment having been purchased, the cost for this should now gradually diminish. Funds could be generated from participation in multicentre international research studies in spinal injuries, given the high number of spinal cord injured, or through fund raising. The appropriate administrative framework has to be set up.

It is not a handicap to have limited sophisticated tools. CT scan and MRI are obviously useful for certain diagnoses but most of the time are possibly, in the context of developing nations, luxury items more useful to doctors than for patients.

The unit does not have functional electrical stimulation or computerised environmental control systems, and has made a deliberate choice to use human resources and simple means to treat these patients.

The traditional and systematic objection to this type of programme is the cost of treating relatively few patients, when the same funds would be more useful in solving famine or launching vaccination programmes. No injury, however, can be more devastating to the individual and the community than spinal cord damage. In a country with major economic problems, poor welfare programmes and unadapted or wheelchair inaccessible houses, a spinal cord injured person is indeed an additional burden to the family; but under which humanitarian principles should an individual be deprived of a right to live in dignity? Should discrimination always exist between those born in the West and the East? Why should there be double standards?

The suggested planning is to wait until the basic health problems are solved before getting involved in 'luxury medicine'. Does anybody sincerely believe that comprehensive healthcare will be provided to all by the year 2000 with so much shameful lack of coordination throughout the world? Competition among nations, international and nongovernmental organisations and individuals transforms the most enthusiastic fieldworkers into pessimistic individuals regarding the future of healthcare.

The federation spinal team is not disputing the importance of famine and vaccination, but is trying to contribute to the alleviation of human suffering in another important area of clinical and social medicine.

\section{Acknowledgements}

We would like to put on record the excellent collaboration of the hospital and the Romanian authorities, as well as the positive contribution of the expatriate and Romanian staff of the spinal injury project. 


\section{Bibliography}

Chacko V, Joseph B, Mohanty SP, Jacob T (1986) Management of spinal cord injury in a general hospital in rural India. Paraplegia 24: 330-335.

Frankel (1987) Spinal cord injury. Paraplegia 25: 239-240.

Meinecke FW (1990) The Spinal Cord Injuries Centre Hamburg. Paraplegia 28: 371-379.

Nelson DN (1992) Romania After Tyranny. Westview Press, Oxford.

Petropoulou CB, Rapidi ChAG, Beltsios M, Karantonis G, Lampiris PrF (1992) The management of spinal cord injury in Greece. Paraplegia 30: 135-138.

Somasundaraman O, Balakrishnan S, Ravindran OS, Shanmugasundaram (1992) A psychological study of spinal cord injured patients involved in the Madras Paraplegia Project. Paraplegia 30: 799-802.

Wang D, Wu X, Shi G, Wang Y (1990) China's first total care unit for the spinal cord injured. Paraplegia 28: 318-320.

Yarkony GM, Roth ES, Meyer PR, Lovel L, Heinemann AW, Betts HG (1990) Spinal cord injury care system: fifteen-year experience at the Rehabilitation Institute of Chicago. Paraplegia 28: 321-329. 